\title{
Occult Hepatitis C Virus Infection in Patients With Autoimmune Hepatitis
}

\author{
Mohammad Saeid Rezaee Zavareh ${ }^{1,2}$; Seyed Moayed Alavian ${ }^{2,}$; Hamidreza Karimisari ${ }^{1}$; \\ Mostafa Shafiei ${ }^{2}$; Seyed Yasser Saiedi Hosseini ${ }^{2}$ \\ ${ }^{1}$ Students' Research Committee, Baqiyatallah University of Medical Sciences, Tehran, IR Iran \\ ${ }^{2}$ Middle East Liver Diseases Center (MELD), Tehran, IR Iran \\ *Corresponding Author: Seyed Moayed Alavian, Middle East Liver Diseases Center (MELD), Tehran, IR Iran. Tel: +98-2188945186, Fax:+98-2188945188, E-mail: editor@hepatmon.com
}

Received: November 10, 2013; Revised: December 27, 2013; Accepted: February 24, 2014

\begin{abstract}
Background: Occult hepatitis C virus infection (OCI) is recognized by finding hepatitis C virus (HCV) RNA in hepatocytes without detectable anti-HCV antibodies and viral RNA in plasma. Autoimmune hepatitis (AIH) is a chronic and generally progressive disease without exactly-identified etiology.

Objectives: This study aimed to determine the prevalence of OCI among patients with AIH and to evaluate the tests used to rule out HCV infection in diagnosing AIH.

Patients and Methods: Between July 2012 to February 2013, 35 Iranian patients with AIH who attended Tehran Hepatitis Center were investigated. For identifying OCI, detection of HCV RNA in both ultracentrifuged serum samples and peripheral blood mononuclear cells (PBMCs) was used. Data analysis was performed using SPSS.

Results: Six males and 29 females with mean disease duration of $77.1 \pm 39.5$ month and mean age of $43.62 \pm 12.67$ years were investigated. All cases were negative for anti-HCV antibody and we could not find any HCV RNA in ultracentrifuged serum samples and PBMCs.

Conclusions:With our laboratory diagnostic method, it seems that there are no cases of OCI in patients with AIH. However, we recommend further studies with more samples and more precise laboratory method.
\end{abstract}

Keywords:Prevalence; Hepatitis C virus; Autoimmune Hepatitis; Infection; Diagnosis; Clinical Laboratory Technique

\section{Background}

In 2004, Castillo et al. defined a new entity of chronic Hepatitis C virus (HCV) infection, ie, occult HCV infection (OCI), in which HCV RNA can be found in hepatocytes and in peripheral blood mononuclear cells (PBMCs) in nearly $70 \%$ of patients without detectable anti-HCV antibodies and viral RNA in plasma by usual tests $(1,2)$. Finding of HCV RNA in hepatocytes is the gold standard and the most precise method for diagnosing OCI; however, the liver biopsy is aggressive. Hence, we can use an alternative method that is recommended for diagnosis of OCI, which is finding of HCV RNA in PBMCs and in ultracentrifuged serum when liver biopsy is not available (3). OCI is reported in patient with cryptogenic liver disease, patients on hemodialysis, and family members of patients with OCI; however, it has been reported in healthy people without any liver disease too $(1,4)$.

OCI can result in minimal changes in liver tissue and although there are some reports of liver cirrhosis and hepatocellular carcinoma due to OCI, it is less severe than HCV infection is. It seems that all HCV genotypes (HCV-1 through HCV-6) can make OCI and it can occurs worldwide (5). Sometimes, differentiation between HCV infection and autoimmune hepatitis (AIH) is difficult (6). AIH is a chronic and generally progressive disease without any exactly-identified etiology, which is distrib- uted worldwide and is more common in females than in males. It is diagnosed by histopathologic changes (interface hepatitis), clinical features, and elevated transaminase, immunoglobulins (Ig), and circulating autoantibodies $(7,8)$. Based on autoantibodies, AIH is categorized in two major form: type 1 is characterized by the presence of circulating antinuclear antibodies (ANA) and smooth muscle antibodies (SMA); and type 2 is determined by the presence of anti-liver-kidney microsomal 1 (LKM-1) and anti-liver cytosol 1 (ALC-1) antibodies (6).

Some viruses, particularly HCV, can induce autoimmune diseases (6) and HCV in some patients with chronic HCV infection can induce autoantibodies (ANA, SMA and antiLKM-1) and consequently, autoimmune hepatitis $(6,9$, 10). SMA, ANA, and with lower prevalence, anti-LKM-1 have been reported in a different populations with chronic $\mathrm{HCV}$ infection in different studies $(10,11)$. Moreover, AIH has been reported in some patients with HIV/HCV coinfection (12).

There are similarities between cytochrome P450 (CYP) 2D6 (target antigen of LKM-1 antibody) sequence and HCV core; therefore, HCV core might have a role in molecular mimicry theory and may be a cause of autoimmune reaction and developing AIH type 2 (13). On the other hand, both HCV antibodies and HCV RNA can be found in a

Copyright (C) 2014, Kowsar Corp;; Published by Kowsar Corp. This is an open-access article distributed under the terms of the Creative Commons Attribution License, which permits unrestricted use, distribution, and reproduction in any medium, provided the original work is properly cited. 
meaningful proportion of patients with AIH suggesting that HCV might have some role in autoimmune response and developing autoimmune hepatitis $(13,14)$.

Finally, another important aspect of the association between $\mathrm{AIH}$ and $\mathrm{OCI}$ is the existence of opposite therapeutic strategy for each one $(6,15)$. Although interferon, as an antiviral medication, is used for treatment of patients with HCV infection, it can have some effects on autoreactivity of T cells and therefore, after continued exposure to interferon, it can lead to induction of autoimmune reactions and developing or worsening of autoimmune hepatitis (16). In contrast, used corticosteroid for treatment of AIH can result in developing HCV infection (17).

\section{Objectives}

This study aimed to determine the prevalence of $\mathrm{OCI}$ among Iranian patients with $\mathrm{AIH}$ and with considering $\mathrm{OCI}$, it aimed to evaluate the tests used to rule out HCV infection in diagnosing AIH.

\section{Patients and Methods}

\subsection{Patients}

Between July 2012 to February 2013, 35 Iranian patients with $\mathrm{AIH}$, who attended Tehran Hepatitis Center, were enrolled in this descriptive cross-sectional study. Based on the defined criteria by the International Autoimmune Hepatitis Group (IAIHG) (18), their disease had been confirmed in our center prior to this study and they were under treatment.

\subsection{Data Collection}

We collected necessary data from each patient's medical file in our database. They included some demographic information, laboratory tests including aspartate aminotransferase (AST), alanine aminotransferase (ALT), alkaline phosphatase (ALKP), platelet (PLT), serum $\gamma$-globulin (GGB), serum albumin, total and direct bilirubin, prothrombin time (PT), ferritin, IgG, IgA, IgM, and level of antibodies including ANA, SMA, LKM-1 (a titer of $\geq 1: 40$ was considered as positive result)(19). We also extracted stage and grade of liver biopsies for some patients with available results in our database.

\subsection{OCI Identification}

We used detection of HCV RNA in both ultracentrifuged serum samples and PBMCs. We obtained an informed consent form each patient. Our laboratory method for HCV RNA extraction and detection and OCI identification (primers, kits, etc) was similar to the study by BokharaeiSalim et al. (1).

\subsection{Data Analysis}

Finally, data were analyzed using SPSS version 17 (SPSS
Inc., Chicago, IL, USA). We expressed continuous variables in mean \pm standard deviation (SD) and categorical variables in frequency (percentage).

\section{Results}

In our study, 35 patients with AIH (6 males and 29 females), mean disease duration of $77.1 \pm 39.5$ months, and mean age of $43.62 \pm 12.67$ years were evaluated. Three patients (8.6\%) were smoker, 8.6\% had a history of cirrhosis, and one patient $(2.8 \%)$ was alcohol abuser. Twenty patients (57.1\%) had fatigue, 24 (68.6\%) had jaundice, 21 (60\%) had pruritus, and 14 (40\%) had myalgia. According to the available data on autoantibodies, ten patients $(28.6 \%)$ had positive results for ASMA and 17 (48.6\%) for ANA. In all cases, only two patients (5.7\%) had positive results for both ANA and ASMA. One patient (2.8\%) had positive results for LKM-1. The mean grade of liver biopsy was $6.5 \pm 4.5$ and mean stage was 3.2 \pm 2.6 . Mean of laboratory variables are shown in Table 1. All cases had negative results for antiHCV antibody and we could not detect any HCV RNA in both ultracentrifuged serum samples and PBMCs.

\begin{tabular}{|c|c|}
\hline Laboratory Test & Mean \pm SD \\
\hline AST, $\mu / \mathbf{L}$ & $281.31 \pm 373.79$ \\
\hline ALT, $\mu / \mathbf{L}$ & $297.09 \pm 390.88$ \\
\hline $\mathbf{A L K P}, \mu / \mathbf{L}$ & $423.54 \pm 352.67$ \\
\hline Platelet, $1000 / \mathrm{mm}$ & $231 \pm 80$ \\
\hline Serum $\gamma$-globulin, g/l & $70.3 \pm 104.3$ \\
\hline Serum albumin, g/l & $39.6 \pm 05.3$ \\
\hline Total bilirubin, $\mu \mathrm{mol} / 1$ & $46.86 \pm 53.52$ \\
\hline Direct bilirubin, $\mu \mathrm{mol} / \mathbf{l}$ & $20 \pm 28.89$ \\
\hline PT, s & $13.40 \pm 3.02$ \\
\hline Ferriti & $76.98 \pm 68.17$ \\
\hline IgG, g/l & $17.24 \pm 15.13$ \\
\hline IgA, g/l & $2.39 \pm 1.34$ \\
\hline IgM, g/l & $1.56 \pm 0.98$ \\
\hline $\begin{array}{l}\text { a Abbreviations: AST, aspa } \\
\text { aminotransferase; ALKP, alkali } \\
\text { and Ig, immunoglobulin. }\end{array}$ & $\begin{array}{l}\text { ransferase; ALT, alanine } \\
\text { se; PT, prothrombin time; }\end{array}$ \\
\hline
\end{tabular}

\section{Discussion}

To the best of our knowledge, it was the first report about prevalence of $\mathrm{OCI}$ in $\mathrm{AIH}$ patients. Until now, some studies have been conducted on OCI in patients with cryptogenic liver disease, patients on hemodialysis, and family members of patients with OCI. On the other hand, it has been shown that some patients with AIH are infected with occult hepatitis B virus (20). In this study, according to our diagnostic method, there were no cases of OCI in patients with AIH. It should be emphasized that our method for diagnosing OCI was detection of HCV RNA 
in both ultracentrifuged serum samples and PBMCs. The gold standard for diagnosis of OCI is probing HCV RNA in hepatocytes; however, the data on liver biopsy were not available for all patients and therefore, we used this suggested alternative method (3). It should be noted that at the time of study, all of the patients were under treatment for AIH.

For diagnosis of AIH, first we must rule out some disease, especially viral hepatitis like HCV infection by checking the anti-HCV antibody (18). Today, OCI is a cause of cryptogenic liver disease (1). Nevertheless, instead of assessing anti-HCV antibody, OCI is diagnosed with the aforementioned methods. According to the result of our study, there were no cases of OCI in patients with AIH and therefore, it seems that there may be no need to evaluate the OCI and usage of its diagnostic methods in AIH. However, two important issues should be taken into account: the sample size of our study and our diagnostic method, namely, detection of HCV RNA in PBMCs and in ultracentrifuged serum. It was reported that combination of these two diagnostic methods can lead to diagnosing of about $85 \%$ of OCI cases (3). Then, for making a better decision on using OCI diagnostic method in routine diagnostic workup of $\mathrm{AIH}$, more studies with more sample size and more accurate diagnostic approaches are needed.

\section{Acknowledgements}

We are very grateful to the patients for participating in this study.

\section{Authors' Contributions}

Mohammad Saeid Rezaee Zavareh: study concept and design, acquisition of data, analysis and interpretation of data, and drafting the manuscript. Seyed Moayed Alavian: interpretation of data, critical revision of the manuscript for important intellectual content, and study supervision. Hamidreza Karimisari: acquisition of data, statistical analysis, and critical revision of the manuscript for important intellectual content. Mostafa Shafiei: study concept and design, acquisition of data, and drafting the manuscript. Seyed Yasser Saiedi Hosseini: study concept and design, analysis and interpretation of data, and drafting the manuscript.

\section{References}

1. Bokharaei-Salim F, Keyvani H, Monavari SH, Alavian SM, Madjd $\mathrm{Z}$, Toosi MN, et al. Occult hepatitis $\mathrm{C}$ virus infection in Ira- nian patients with cryptogenic liver disease. J Med Virol. 2011; 83(6):989-95.

2. Castillo I, Pardo M, Bartolome J, Ortiz-Movilla N, Rodriguez-Inigo $\mathrm{E}$, de Lucas S, et al. Occult hepatitis C virus infection in patients in whom the etiology of persistently abnormal results of liverfunction tests is unknown. J Infect Dis. 2004;189(1):7-14.

3. Castillo I, Bartolome J, Quiroga JA, Barril G, Carreno V. Diagnosis of occult hepatitis $\mathrm{C}$ without the need for a liver biopsy. J Med Virol. 2010;82(9):1554-9.

4. Carreno Garcia V, Nebreda JB, Aguilar IC, Quiroga Estevez JA [Occult hepatitis C virus infection]. Enferm Infecc Microbiol Clin. 2011;29 Suppl 3:14-9.

5. Carreno V, Bartolome J, Castillo I, Quiroga JA. New perspectives in occult hepatitis C virus infection. World J Gastroenterol. 2012;18(23):2887-94

6. Jadali Z, Alavian SM. Autoimmune diseases co-existing with hepatitis C virus infection. Iran J Allergy Asthma Immunol. 2010;9(4):191-206.

7. Krawitt EL. Autoimmune hepatitis. NEnglJMed.2006;354(1):54-66.

8. Gossard AA, Lindor KD. Autoimmune hepatitis: a review. J Gastroenterol. 2012;47(5):498-503.

9. Bai L, Feng ZR, Lu HY, Li WG, Yu M, Xu XY. Prevalence of antinuclear and anti-liver-kidney-microsome type-1 antibodies in patients with chronic hepatitis C in China. Chin Med J (Engl). 2009;122(1):5-9.

10. Cassani F, Cataleta M, Valentini P, Muratori P, Giostra F, Francesconi R, et al. Serum autoantibodies in chronic hepatitis C: comparison with autoimmune hepatitis and impact on the disease profile. Hepatology. 1997;26(3):561-6.

11. Pavic S, Simonovic J, Boricic I, Svirtlih N. [Autoantibodies characteristic for autoimmune hepatitis found in chronic hepatitis $\mathrm{C}$ ]. Srp Arh Celok Lek. 2003;131(11-12):437-42.

12. Vispo E, Maida I, Moreno A, Barreiro P, Soriano V. Autoimmune hepatitis induced by pegylated interferon in an HIV-infected patient with chronic hepatitis C. J Antimicrob Chemother 2008;62(6):1470-2.

13. Kammer AR, van der Burg SH, Grabscheid B, Hunziker IP, Kwappenberg KM, Reichen J, et al. Molecular mimicry of human cytochrome $\mathrm{P} 450$ by hepatitis $\mathrm{C}$ virus at the level of cytotoxic $\mathrm{T}$ cell recognition. J Exp Med.1999;190(2):169-76.

14. Michitaka K, Durazzo M, Tillmann HL, Walker D, Philipp T, Manns MP. Analysis of hepatitis $C$ virus genome in patients with autoimmune hepatitis type 2. Gastroenterology. 1994;106(6):1603-10.

15. Heintges T, Niederau C. Differentiation between autoimmune hepatitis and hepatitis C virus related liver disease. Z Gastroenterol. 1993;31(5):285-8.

16. Conrad B. Potential mechanisms of interferon-alpha induced autoimmunity. Autoimmunity. 2003;36(8):519-23.

17. Oeda S, Mizuta T, Isoda H, Kuwashiro T, Oza N, Iwane S, et al. Efficacy of pegylated interferon plus ribavirin in combination with corticosteroid for two cases of combined hepatitis $\mathrm{C}$ and autoimmune hepatitis. Clin J Gastroenterol. 2012;5(2):141-5.

18. Alvarez F, Berg PA, Bianchi FB, Bianchi L, Burroughs AK, Cancado EL, et al. International Autoimmune Hepatitis Group Report: review of criteria for diagnosis of autoimmune hepatitis. J Hepatol. 1999;31(5):929-38.

19. Shafiei M, Alavian SM. Autoimmune hepatitis in Iran: what we know, what we don't know and requirements for better management. Hepat Mon. 2012;12(2):73-6.

20. Georgiadou SP, Zachou K, Liaskos C, Gabeta S, Rigopoulou EI, Dalekos GN. Occult hepatitis B virus infection in patients with autoimmune liver diseases. Liver Int. 2009;29(3):434-42. 